\title{
FEUERBACH: FUNDAMENTOS PARA UMA ÉTICA DA SENSIBILIDADE
}

\begin{abstract}
Ana Selva Albinati ${ }^{1}$
RESUMO

Pretende-se aqui desenvolver os elementos presentes no pensamento de Feuerbach que sustentam uma "ética da sensibilidade" como questionadora de uma ética racionalista, como, por exemplo, a ética do dever de talhe kantiano. A despeito dos limites da filosofia de Feuerbach, reiteradamente identificados por Marx no que se refere à inconciliabilidade no pensamento do autor entre materialismo e história - o que o joga no terreno de um idealismo do gênero humano - , há que se destacar a significação de Feuerbach no percurso de contraposição à mistificação idealista, ao ressaltar a dimensão da corporeidade e dos afetos, ainda que sejam estes tidos em sua naturalidade, como elementos inalienáveis e incontornáveis do agir humano, portanto, insurgindo contra uma forma seca de racionalismo que pretende dicotomizar razão e sensibilidade. O objetivo de nosso trabalho é acompanhar os fundamentos da filosofia sensualista de Feuerbach que lhe permitem concluir por um antropoteísmo, "o coração elevado a entendimento", que se contrapõe à separação entre sensibilidade e entendimento e à sobreposição do segundo sobre o primeiro. Recuperando a significação dos sentidos e das afecções, o autor pretende responder ao idealismo moderno desde Descartes, entendendo-o como uma derivação da teologia que tem a sua consumação na filosofia de Hegel. A afirmação do ponto de partida da filosofia naquilo "que no homem não filosofa", qual seja, a sensibilidade, a finitude, a afecção, prepara o terreno sobre o qual Marx desenvolverá, uma vez feito o apontamento crítico dos limites feuerbachianos, a compreensão da realidade social, incluindo elementos que nos possibilitam pensar a esfera do agir moral em uma perspectiva materialista.
\end{abstract}

Palavras-chave: idealismo, materialismo, ontologia, ética

\begin{abstract}
This work intends to develop the elements presented in Feuerbach's thought which support the notion of "ethics of sensibility" as an opposition of the "rationalist ethics" such as, for instance, the Kantian ethics of duty. Despite the boundaries repeatedly identified by Marx of Feuerbach's philosophy regarding the irreconcilability between materialism and history - putting him in the field of idealism of human gender , it is necessary to highlight the impact of Feuerbach in the path of contraposition to idealist mystification by stressing the dimension of corporeality and affection, even if them are to be considered in its naturality as inalienable and unavoidable elements of human behaviour, thus, criticizing a dry form of rationalism which intends to dichotomize reason and sensibility. The aim of our work is to identify the fundamentals of Feuerbach's sensualist philosophy which allow him to opt for a "anthropotheism", "the heart raised to understanding", which counterpose the separation between sensibility and understanding and the superposition of the latter over the former. Retrieving the meaning of senses and affections, the author intends to interpret the modern idealism as a theological derivation which has its peak on Hegel's philosophy.The affirmation of philosophy's starting point as being "what humans do not philosophize about", being it the sensibility, the finiteness or the affection, sets the stage over which Marx will develop, after indicating Feuerbach's limitations, the notion of social reality, including the elements that allow us to think about the moral acting in a materialist perspective.
\end{abstract}

Key-words: idealism, materialism, ontology, ethics

\footnotetext{
${ }^{1}$ Possui graduação em Filosofia pela Universidade Federal de Minas Gerais (1990), graduação em Ciências Biológicas pela Universidade Federal de Minas Gerais (1981), mestrado (1999) e doutorado (2007) em Filosofia pela Universidade Federal de Minas Gerais. Atualmente é professora do Departamento de Filosofia da Pontifícia Universidade Católica de Minas Gerais.
} 
Ana Selva Albinati

Pretende-se aqui desenvolver os elementos presentes no pensamento de Feuerbach que sustentam uma "ética da sensibilidade" como questionadora de uma ética racionalista, como, por exemplo, a ética do dever de talhe kantiano.

A despeito dos limites da filosofia de Feuerbach, no que se refere à nãocompreensão do caráter histórico da objetividade em sua relação com a subjetividade, há que se destacar a significação de Feuerbach no percurso de contraposição à mistificação idealista, ao ressaltar a dimensão da corporeidade e dos afetos.

Ainda que sejam estes tidos em sua naturalidade, como elementos inalienáveis e incontornáveis do agir humano, o seu pensamento insurge-se contra uma forma seca de racionalismo que pretende dicotomizar razão e sensibilidade.

O objetivo de nosso trabalho é acompanhar os fundamentos da filosofia sensualista de Feuerbach que lhe permitem concluir por um antropoteísmo, "o coração elevado a entendimento", que se contrapõe à separação entre sensibilidade e entendimento e à sobreposição do segundo sobre o primeiro. Recuperando a significação dos sentidos e das afecções, o autor pretende responder ao idealismo moderno desde Descartes, entendendo-o como uma derivação da teologia que tem a sua consumação na filosofia de Hegel.

Procuraremos reconstituir aqui, em traços gerais, essa significação da afetividade no autor, na medida em que entendemos que há, sob o termo "amor" tal como presente nos seus textos, um sentido peculiar que mereceria ainda uma análise mais apurada.

As obras nas quais nos baseamos são A essência do cristianismo, de 1841, os Princípios da filosofia do futuro, de 1843, e as Preleções sobre a essência da religião de 1851.

É conhecido o procedimento feuerbachiano de recondução da teologia à antropologia, ou seja, a sua forma de considerar o fenômeno religioso, em suas figuras e expressões, como uma alienação dos atributos humanos. Dessa forma, os indivíduos passam a reconhecer em algo exterior a si, a expressão mais adequada e desejável de seus próprios atributos. Deus toma o lugar abstrato da generidade humana, e como afirma o autor: "A nossa intenção é exatamente provar que a oposição entre o divino e o humano é apenas ilusória, i.é, nada mais é do que a oposição entre a essência humana e o indivíduo humano.” (Feuerbach, 1997, p.56-7).

O passo importante que é dado é a dissolução do sobrenatural no natural. Feuerbach localiza na essência humana as qualidades do divino, e reconhece uma

\begin{tabular}{|c|c|c|c|c|}
\hline Q Ronista Dialectus & Ano 2 & n. 6 & Janeiro - Agosto 2015 & p. $75-84$ \\
\hline
\end{tabular}


Ana Selva Albinati

oposição entre essa essência e o indivíduo, tal qual se realiza. Falta a ele perguntar pelas razões dessa irrealização, dessa cisão. Ou seja, o autor mantém-se nesse movimento de ultrapassagem do idealismo no terreno de um naturalismo que não comporta em si a historicidade.

Tal limite do pensamento feuerbachiano é identificado por Marx, a partir de seu ônus, que é o fato de que ele tenha, como conseqüência, que manter a noção de essência genérica idealizada, como um refúgio diante da individualidade não realizada, na medida em que Feuerbach não procura as razões dessa cisão na constituição simultânea e contraditória do indivíduo e do gênero na forma da vida social.

Essa essência humana é definida como razão, coração e vontade. Razão e coração são atributos que se encontram cindidos, correspondendo o primeiro à capacidade de apreensão da universalidade própria do gênero humano e o segundo à expressão subjetiva e própria dos interesses dos indivíduos.

A despeito da forma a-histórica com que o autor se refere à essência humana, interessa-nos aqui compreender os elementos da sua reflexão a respeito da antítese razão-coração e sua identificação, ainda que problemática, da vida concreta, finita, sensível, como ontologicamente primária em relação ao pensamento.

Se a alienação religiosa é resultado da cisão entre essência genérica e individualidade, é a marca dessa cisão - ao mesmo tempo que sua solução ilusória -, Feuerbach considera que essa solução ilusória alcança a sua efetividade de forma mais abrangente que a própria filosofia em seu caráter racional e abstrato.

Enquanto a religião toca na separação que se consagra na tradição filosófica entre razão e sensibilidade, e de certa forma a resolve a partir da sua unidade nas figuras de Deus Pai e Deus Filho, a filosofia moderna eleva o "eu penso", a razão, o espírito, a um princípio auto-subsistente, em detrimento da materialidade sensível.

\footnotetext{
Os sentidos, diz Descartes, não fornecem nenhuma realidade verdadeira, nenhuma essência, nenhuma certeza - só o entendimento separado dos sentidos proporciona a verdade. Donde promana esta cisão entre o entendimento e os sentidos? Deriva apenas da teologia. (Feuerbach, 1988, p. 61)
}

A relação entre religião e filosofia é posta nos seguintes termos: "A filosofia moderna derivou da teologia - nada mais é do que a teologia resolvida e metamorfoseada em filosofia." (Feuerbach, 1988, p. 60)

\begin{tabular}{|l|l|l|l|l|}
\hline Rovista Cialectus & Ano 2 & n. 6 & Janeiro - Agosto 2015 & p. 75-84 \\
\hline
\end{tabular}


Ana Selva Albinati

No entanto, a teologia, enquanto reflexão dogmática sobre o fenômeno religioso, deixa escapar a essência da religiosidade, que seria exatamente o coração e suas razões. Nesse sentido, a sua afirmação da figura do filho na trindade religiosa como a verdade da religião vem reforçar esse entendimento.

Se há, por parte de Feuerbach, o reconhecimento do caráter universal da razão contra o particularismo dos sentimentos, há também o reconhecimento de que a exclusividade do princípio racional não dá conta do caráter humano dos indivíduos, de tal forma a mostrar-se impermeável aos anseios humanos, seja na forma de uma filosofia abstrata ou de sua conseqüente ética racionalista.

Feuerbach compreende a ética racionalista como a expressão de um déficit de realização da essência humana, a ser corrigido por uma nova filosofia que se torne uma nova religião, que alie razão e sentimentos no plano da imanência, da concretude, do finito. Contra o racionalismo abstrato, ele diz:

\footnotetext{
Homens puramente racionais, homens que para nós simbolizam e personificam a essência da razão, ainda que num aspecto unilateral, mas exatamente por isso característico, são isentos de angústia, paixões e excessos dos homens sentimentais; não se prendem a nenhum objeto finito, i. é, determinado, de maneira passional; não se empenham, são livres. (Feuerbach, 1997, p. 78).
}

$\mathrm{O}$ autor aponta nessa passagem o princípio da ética kantiana do dever, a liberdade como independência da sensibilidade.

Mas tal liberdade é mera abstração, ou melhor, é atributo apenas de um ser abstrato, o atributo da razão abstrata. A fortaleza que Kant ergue a partir da razão pretende tornar a moral humana asséptica, impenetrável aos sentidos.

Há, por parte de Feuerbach, o reconhecimento do caráter universal da razão contra o particularismo dos sentimentos, mas tal reconhecimento se dá como reconhecimento de uma cisão que necessita ser reconciliada nos homens.

Tal reconciliação é, na sua análise do fenômeno religioso, alcançada de forma espelhada na idéia de Trindade, onde se tem Deus Pai e do Deus Filho, razão e coração. O sentido dessa duplicidade em um único ser é o da relação ineliminável entre esses dois atributos, agora em uma forma conciliada: "O filho nada é sem o pai, o pai nada é sem o filho, o Espírito Santo, que em geral perturba a simetria, expressa apenas a relação de ambos entre si." (Feuerbach, 1997, p. 275).

\begin{tabular}{|l|l|l|l|l|}
\hline Qenista Dialectus & Ano 2 & n. 6 & Janeiro - Agosto 2015 & p. 75-84 \\
\hline
\end{tabular}


Ana Selva Albinati

A filosofia moderna, herdeira da teologia, se inicia com a cisão entre sujeito e objeto e sua incomunicabilidade, e se consuma como uma filosofia da identidade a partir do ser abstrato, infinito, que daria sentido ao ser concreto, finito.

Esse percurso da filosofia moderna é criticado por Feuerbach como sendo a forma invertida de consideração do ser e de seu predicado, o pensamento.

Uma nova filosofia, à qual o autor se propunha, teria que refundar a relação imediata, sensível, intuitiva, entre ser e pensar, reconhecendo a primazia do ser e a legitimidade dos sentidos, de forma a apresentar-se como uma nova religião na medida em que assimilasse a essência da religião (a reconciliação entre afetividade e razão) em sua naturalidade, uma vez desfeitas as ilusões da teologia.

Tal perspectiva pode ser melhor observada quando o autor trata de Deus como expressão da perfeição moral.

Ao contrário dos outros atributos de Deus, como a plenipotência e a eternidade, a consciência da perfeição moral opera como uma lei para o indivíduo na medida em que não se refere à natureza e portanto, independe dela, mas se refere apenas à vontade do indivíduo, está sob o seu poder, portanto. Nesse sentido, "é uma idéia que me coloca em tensão e numa cisão comigo mesmo, porque ao me proclamar o que eu devo ser, dizme ela ao mesmo tempo e francamente o que eu não sou." (Feuerbach, 1997, p. 90)

Não por acaso, Kant pensa Deus como a lei personificada da moralidade.

No caso da ética kantiana, a distância reconhecida entre a vontade humana e a vontade santa, que se oferece como modelar, é tão grande que precisamos do imperativo categórico para guiar a vontade humana unicamente pelo dever, sem consideração pelas afecções.

Dessa forma, observa Feuerbach: "Kant reivindica, pois, efetivamente, os predicados da divindade para a vontade.” (Feuerbach, 1988, p.59-60)

Tal transposição dos predicados divinos para a vontade interdita a ordem do sensível e do natural, donde tem-se que:

O idealismo kantiano, onde as coisas se regulam pelo entendimento e não o entendimento pelas coisas, nada mais é, pois, do que a realização da representação teológica do entendimento divino, o qual não é determinado pelas coisas mas, pelo contrário, as determina. (Feuerbach, 1988, p.59).

O grau de dificuldade de tal conduta moral se traduz em uma frustração frente a um ideal irrealizável.

\begin{tabular}{|l|l|l|l|l|}
\hline Qenista Dialectus & Ano 2 & n. 6 & Janeiro - Agosto 2015 & p. 75-84 \\
\hline
\end{tabular}


Ana Selva Albinati

A superação dessa frustração se daria, segundo Feuerbach, pela reconciliação com a sensibilidade, e mais precisamente, pelo reconhecimento da primazia do sensível, o que, nas palavras do autor, se configura pela consciência do amor como a verdade mais elevada.

Tal consciência estaria presente na representação religiosa, através da consideração da divindade não só como lei da razão, mas também como um ser que ama.

Essa humanização se traduz na compaixão: "A lei condena, mas o coração se compadece do pecador. A lei só me afirma como um ser abstrato, mas o coração como um ser real." (Feuerbach, 1997, p.90).

Ou de forma mais sintética: "A misericórdia é o senso de justiça dos sentidos". (Feuerbach, 1997, p.91).

Dessa forma, afirma o autor que "Um ser unicamente moral não pode perdoar o que é contra a lei da moralidade", o perdão é obra de um "ser não moral", "um ser mais do que moral", “um ser humano". (Feuerbach, 1997, p.91).

Não seria um "ser amoral", mas um ser mais do que moral, ou seja, um ser também sensível, que não se rege por uma moralidade abstrata, racional, universal.

“A contemplação de Deus como um ser humano é o mistério da encarnação, do Deus que se torna carne e homem." (Feuerbach, 1997, p.93). Essa segunda pessoa da trindade é a pessoa verdadeira da religião.

Deus pai e Deus filho expressa a relação eu-tu. "Eu é razão, Tu é amor; só razão com amor e amor com razão é espírito, é o homem total." (Feuerbach, 1997, p.111). A terceira pessoa da trindade, por sua vez, expressa o amor recíproco de ambas as pessoas divinas, é a unidade de filho e pai, o conceito da comunidade.

Ele faz uma relação entre filosofia abstrata, racionalista e religião que, em sua forma alienada, compreende e assimila a afetividade, o ser concreto: "Consciência, razão, vontade, amor no sentido de seres ou qualidades abstratas só pertencem à filosofia abstrata. Mas a religião é a consciência que o homem tem de si em sua totalidade viva." (Feuerbach, 1997, p.110)

O problema da religião é que ela comporta um sobre naturalismo que se traduz na forma de uma onipotência frente à ordem natural. A análise empreendida pelo autor a esse respeito nos aponta o aspecto nodal da questão: o desejo humano para além da razão natural. Nesse sentido, o próprio amor como princípio de reconhecimento da

\begin{tabular}{|l|l|l|l|l|}
\hline Q & Donista \\
\hline
\end{tabular}


Ana Selva Albinati

objetividade se transforma na imaginação religiosa em amor cristão, capaz de subverter a causalidade natural em prol do atendimento ao desejo individual na forma da graça.

Esse seria o princípio subjetivo, psicológico da religião: "Um Deus é essencialmente um ser que realiza os desejos do homem." (Feuerbach, 1989, p.224).

Ao pensar em uma filosofia do futuro, ele diz que a filosofia deve se tornar religião, reunificar razão e amor para além do amor cristão em sua arbitrariedade e da razão pura, isenta de contaminação sensível: "Para substituir a religião, a filosofia deve tornar-se religião enquanto filosofia, deve introduzir em si mesma, de um modo a ela conforme, o que constitui a essência da religião, o que faz a vantagem da religião sobre a filosofia.” (Feuerbach, 1988, p.15).

Isso porque: “A nova filosofia é o coração elevado ao entendimento. O coração não quer objetos e seres abstratos, metafísicos ou teológicos - quer objetos e seres reais e sensíveis.” (Feuerbach, 1988, p.81).

O coração elevado ao entendimento é muito mais do que uma sentimentalidade em Feuerbach, é o vínculo do pensar com o real, com o concreto, é a afirmação da primazia do ser sobre o pensar, e da afecção do ser sobre o indivíduo pensante. Contra a filosofia racionalista, centrada no eu, o mundo é descortinado como originário pelos sentidos: "É só pelos sentidos que o eu é não-eu”. (Feuerbach, 1988, p.79).

Sensibilidade e razão se expressariam assim de forma cindida na filosofia moderna ("o racionalista possui uma vontade divina, mas sem as condições e manifestações necessárias da vontade, sem os nervos e músculos” (Feuerbach, 1989, p.225); e na forma de uma reconciliação fantasiosa na religião.

O exame, por parte do autor, dessas duas formas de expressão da condição do indivíduo frente ao gênero, pretende alcançar a mediação natural e originária entre sensibilidade e razão, o que constituiria os fundamentos de uma filosofia do futuro.

Nesse sentido, um aspecto fecundo a se atentar é a significação do termo "amor" tão amplamente utilizado pelo autor.

Em Preleções sobre a essência da religião, Feuerbach pretende rever o que seria, nas suas palavras, "uma grande falha" da Essência do cristianismo, qual seja, o ter negligenciado a natureza e ter considerado apenas as forças que fundamentam o ser humano em contraste com a natureza.

Ao definir a sua "doutrina religião, filosofia, ou como quiserdes chamar", ele a definirá de forma sintética em "teologia é antropologia", para em um momento seguinte expressá-la em duas palavras: natureza e homem.

\begin{tabular}{|l|l|l|l|l|}
\hline Q & Anotita 2 & n. 6 & Janeiro - Agosto 2015 & p. 75-84 \\
\hline
\end{tabular}


Ana Selva Albinati

O reconhecimento da objetividade natural como um ser em si, independente da consciência, constitui o elemento ontologicamente primário sobre o qual se desenvolvem as relações humanas. O termo "amor" recebe nesse contexto uma significação mais ampla: diz respeito à dependência e interesse pelo não-eu, pelo mundo, diz respeito ao caráter necessitário dos seres objetivos em suas mútuas relações.

Trata-se aqui da proposição do ser objetivo, concreto, finito, como ponto de partida da filosofia. Amor não tem o sentido restrito de amor entre pessoas, embora inclua isso também.

Uma ética da sensibilidade não significa, assim, um pieguismo da misericórdia ou uma arbitrariedade da vontade, como pensava Kant ao dizer da volubilidade da vontade diante das inclinações, mas um reconhecimento da sensibilidade que afirma o humano a partir da individualidade concreta, objetiva, correlacionada à objetividade. Os sentidos são as portas de apreensão da objetividade. O amor é a afecção que traduz a dependência humana da objetividade, seja na forma dos seres naturais, seja na forma dos outros seres humanos.

Esse elo que liga o sujeito que pensa ao mundo objetivo, e o faz reconhecer o outro como um não-eu é o fundamento da ciência natural, do resgate do naturalismo contra a abordagem do sentimento como arbitrariedade (que é identificado por ele no amor cristão na forma da graça).

A interrupção dessa relação amorosa, que nos devolve à consciência da dependência da objetividade, se revela na dor pela ausência da relação desejada, como ele ilustra a partir do exemplo do estômago que atrita as suas paredes entre si em vez de atritar o alimento. (Feuerbach, 1988, p.81).

O caráter da finitude que se revela na dependência, no fato de não-ser absoluto, é o que o homem aliena de si na forma de Deus filho, como possibilidade de reconhecimento de si enquanto paixão na relação com o eu feito Deus pai como razão.

Se o amor aponta essa dependência sensível, o egoísmo seria a atitude natural na satisfação dessa dependência. Mas também esse egoísmo recebe uma conotação própria na filosofia feuerbachiana. Trata-se do "egoísmo necessário, não moral, mas metafísico, isto é, fundado na essência do homem sem seu saber e querer, o egoísmo sem o qual o homem não pode viver, porque para viver devo apropriar-me constantemente do que me é conveniente." (Feuerbach, 1989, p.50).

Se aqui transparece o seu naturalismo a-histórico, metafísico, que pressupõe uma essência humana naturalmente egoísta, é importante ressaltar que o egoísmo no

\begin{tabular}{|l|l|l|l|l|}
\hline Q Povista Dialectus & Ano 2 & n. 6 & Janeiro - Agosto 2015 & p. 75-84 \\
\hline
\end{tabular}


Ana Selva Albinati

sentido aqui retratado significa simplesmente o atendimento ao caráter necessitário da vida, do seres naturais e finitos, que os coloca em uma situação ambivalente de servo e senhor perante a natureza. (Feuerbach, 1989, p.73).

Amor, reconhecimento da dependência da objetividade, interesse, egoísmo são as bases naturais sobre as quais, observa o autor, deveriam se fundar a moral e o direito. (Feuerbach, 1989, p.257).

Embora Feuerbach não se encaminhe na análise histórico-social acerca desse "egoísmo natural", é interessante destacar a relação que o autor aponta entre o exercício desse egoísmo e a questão social: "O bem nada mais é que aquilo que corresponde ao egoísmo de todos os homens e o mal nada mais é que aquilo que corresponde e condiz com o egoísmo de classes humanas isoladas, consequentemente, às custas dos outros." (Feuerbach, 1989, p.255).

A rápida referência à questão da desigualdade social surge no contexto em que o autor se refere à situação do proletariado como uma circunstância a ser transformada e não a ser aceita como uma predestinação, um "acaso personificado".

Dessa forma, o autor encontra-se próximo, no tocante a esta questão, do materialismo francês de Helvetius e d’Holbach, que tomam o egoísmo como uma expressão da naturalidade humana, e edificam a moralidade sobre a possibilidade de um egoísmo racional, socialmente educado.

Os limites de tal entendimento, de tal naturalismo, de tal sensualismo, foram devidamente identificados por Marx.

Mas o grande mérito de Feuerbach está na reposição da relação entre ser e pensar: "Devemos apenas não separar dos sentidos o entendimento para encontrar no sensível o supra-sensível, isto é, o espírito e a razão.” (Feuerbach, 1988, p.83).

A afirmação do ponto de partida da filosofia naquilo "que no homem não filosofa", qual seja, a sensibilidade, a finitude, a afecção, prepara o terreno sobre o qual Marx desenvolverá, uma vez feito o apontamento crítico dos limites feuerbachianos, a compreensão da realidade social, incluindo elementos que nos possibilitam pensar a esfera do agir moral em uma perspectiva materialista.

\section{Referências bibliográficas}

FEUERBACH, Ludwig. Princípios da filosofia do futuro. Tradução:Artur Morão. Lisboa: edições 70, 1988.

\begin{tabular}{|l|l|l|l|l|}
\hline Q Povista Dialectus & Ano 2 & n. 6 & Janeiro - Agosto 2015 & p. 75-84 \\
\hline
\end{tabular}


Ana Selva Albinati

FEUERBACH, Ludwig. Preleções sobre a essência da religião. Tradução: José da Silva Brandão. Campinas: Papirus, 1989.

FEUERBACH, Ludwig. A essência do cristianismo. Tradução: José da Silva Brandão. Campinas: Papirus, 1997.

\begin{tabular}{|c|c|c|c|c|}
\hline Ronista Dialectus & Ano 2 & n. 6 & Janeiro - Agosto 2015 & p. $75-84$ \\
\hline
\end{tabular}

